\title{
O Matemático e a Barata
}

\section{The Mathematician and the Cockroach}

\section{João Ricardo Viola dos Santos ${ }^{\mathrm{a}}$}

a Instituto de Matemática, Universidade Federal de Mato Grosso do Sul, Campo Grande, Brasil - joao.santos@ufms.br

Palavras-chave:

Ficção. Formação de professores. Estéticas e políticas de pesquisa. Modelo dos campos semânticos.

\section{Keywords:}

Fiction. Teacher education Research policies and aesthetics. Model of semantic fields.
Resumo: Três amigos se encontram, não exatamente no mesmo espaço e tempo. Eles falam de suas vidas, profissões, demandas e tarefas diárias. Um $13^{\circ}$ cenário é a formação matemática de professores de matemática. Outro $26^{\circ}$ é um modo de problematizar políticas e estéticas de pesquisa na área de Educação Matemática provocando algumas faíscas, inventando (sendo inventado) outras possibilidades. Qualquer outro cenário pode ser produzido, dependendo do pacto que cada leitor, digo autor deste texto, possa se interessar. Angústias, contradições, suspensões, desconstruções, circunstâncias da formação inicial de professores e de modos de produção/invenção de pesquisa em Educação Matemática são produzidos. Este é o primeiro ato. Pequenas frases (podem) provocam algumas sensações, intensidades, demandas para (possíveis) outros modos de produzir significados. Elas não explicam, nem mesmo de sistematizam algo. Elas apenas estão e, por estarem, constituem possíveis possibilidades. Não indicam, afetam. Não explicam, deixam em suspensão. Este é o segundo ato. Talvez, a ficção possa oferecer outras possibilidades para problematizar (e nos problematizarmos) nossas práticas culturais e nossos movimentos de teorizações. Um modo de ver, produzir, inventar, ser afetado e sentir o que do outro pode ter algum efeito em mim - sempre em tentativas de colocar nossas identidades em risco. Ficção como processo, como movimento. Apenas outro.

Abstract: Three friends meet, not exactly in the same space and time. They talk about their lives, professions, demands and daily tasks. A $13^{\text {th }}$ scenario is the mathematical preparation of mathematics teachers. Another $26^{\text {th }}$ is a way of problematizing research policies and aesthetics in the area of Mathematics Education - provoking some sparks, inventing (being invented) other possibilities. Any other scenario can be produced, depending on the pact that each reader, I say the author of this text, may be interested. Anguish, contradictions, suspensions, deconstructions, circumstances of initial teacher training and modes of production/invention research in Mathematics Education are produced. This is the first act. Small phrases (can) provoke some sensations, intensities, demands for (possible) other ways of producing meanings. They do not explain, nor even systematize, anything. They are only, and because they are, they are possible possibilities. They do not indicate, they affect. They do not explain, they leave in suspension. This is the second act. Perhaps, fiction may offer other possibilities for problematizing (and problematizing ourselves) our cultural practices and our theorization movements. One way of seeing, producing, inventing, being affected, and feeling what about the other can have an effect on me - always in attempts to put our identities at risk. Fiction as a process, as a movement. Just other. 
Vou criar o que me aconteceu. Só porque viver não é relatável. Viver não é vivível. Terei que criar sobre a vida.

E sem mentir. Criar sim, mentir não.

Criar não é imaginação, é correr o grande risco de se ter a realidade. Entender é uma criação, meu único modo.

(Clarice Lispector, Paixão Segundo G H)

Boa tarde Sérgio, tudo bem? Como foi a sua aula hoje? Foi boa, os alunos ficaram quietos, prestaram atenção, consegui demonstrar o teorema do valor intermediário e, aparentemente, eles entenderam. Aparentemente, né?! Passei dois exercícios, discutimos um pouco de matemática; contei um pouco sobre a área de sistemas dinâmicos, suas aplicações e quais perspectivas estão surgindo. Eles gostaram. Fiquei satisfeito, gostei, foi muito bom. Quer café? Vou fazer um para mim e já faço para nós dois. Obrigado, faça sim. Hoje eu estava lendo um artigo muito interessante sobre Topological defect system in $O(n)$ symmetric time-dependent Ginzburg-Landau model. Um chinês, Ying Jiang, que faz parte de um grupo de topólogos muito forte da Ásia, mostrando alguns resultados. Depois fui atrás de mais artigos dele e encontrei coisas muito interessantes. Ele tem um projeto maior e parece um professor obcecado por pesquisa, obcecado por matemática. Fiquei empolgado e passei a tarde inteira pesquisando, olhando trabalhos, pulando de um site para outro, de um artigo para outro. Resolvi alguns resultados básicos de sua pesquisa, olhei outros problemas. Nem vi o tempo passar, nem vi que já era tarde. O tempo voa quando trabalhamos com matemática, não é mesmo? Parece que ela tem uma certa magia de encantamento, uma certa substância que nos enfeitiça. Esquecemos de nós, do mundo, esquecemos de tudo e apenas ficamos concentrados em elaborar estratégias para atacar um determinado problema. O cara, o tal chinês, buscou em três áreas dos sistemas dinâmicos, conseguiu provar uma conjectura, que há muito tempo estava esquecida; depois com ela, enunciou um teorema e com isso conseguiu fazer o que ele queria. Os detalhes são obscuros, mas a estética de sua linguagem, a beleza matemática, o poder de cada palavra, de cada proposição, o artigo como um todo o deixa em posição ímpar, digno de um matemático... Quando consegui desgrudar-me dos problemas do chinês, quando lembrei-me de que existia um mundo além do meu lápis, dos papéis e da tela do meu computador, fui à cantina buscar um salgado, pois já era tarde e eu estava com fome. Olhei as árvores belas, centenárias, grandiosas, senti o frescor do ar do campus com o vento que movimenta as folhas, atentei-me ao silêncio das buzinas e dos barulhos ensurdecedores, avistei alguns estudantes rindo e conversando, possivelmente de alguma cena trágica e cotidiana do mundo de uma república; outros sentados e estudando em grupo; outros, ainda, solitários com livros em mãos. Lembrei-me do nosso tempo de Universidade, Sérgio, de como era bom e de como gostávamos daquela vida. Isso causou um pouco de melancolia: estamos aqui nos arredores da universidade há muito tempo. Há quanto tempo estou aqui, falando 
sobre os mesmos assuntos, vivendo as mesmas cenas, e sempre olhando e imaginando o mundo de dentro da Universidade? Fiquei pensando nisso, viu Sérgio. Às vezes, sentamos aqui, falamos de nossas aulas, de nossas pesquisas, claro que falamos também de futebol, discutimos problemas do departamento, política do país, o futuro das Universidades. Falamos das escolas públicas, da baixa qualidade dos alunos que estão chegando ao curso de matemática. Você se lembra que há uns 10 anos atrás nós tínhamos melhores alunos? Chegavam poucos, isso é fato; mas eles faziam valer a pena. Hoje chegam muitos, o que por um lado é bom, mas a qualidade é muito baixa. Fiquei pensando e apenas pensando... Outro dia eu também me peguei pensando nessa questão que você coloca, de estarmos sempre falando de dentro da Universidade. Veja, meu amigo, apesar de termos apenas um curso de Licenciatura, temos que fazer pesquisa em Matemática, pois nós somos matemáticos. Tanto eu quanto você, passamos duros anos de nossas vidas estudando matemática, fazendo nossos mestrados e doutorados. Eu penso que não temos condições de nos preocuparmos com todos os problemas e mais, olhando-os de lugares distintos. Nossa casa é a Universidade, é aqui que ficamos todas as semanas durante anos e anos. Penso que se conseguirmos dar uma boa aula de Análise, colocar esses alunos para aprenderem mesmo Cálculo Diferencial Integral e desenvolvermos alguns resultados da nossa pesquisa, já está bom. Acho que me dou por satisfeito. Você não acha? Claro, penso nesses outros mundos que estão bem distante de nós. E veja, bem distante é modo de falar, pois tem uma escola pública a dois quarteirões daqui da Universidade. É verdade Sérgio, quando volto para casa vejo os alunos saindo da escola. Mas, voltando, acho que é isso. Contento-me com isso. Talvez, tenhamos que nos contentar com nossas possibilidades. Existem mundos maiores do que o nosso. É, talvez você tenha razão, Sérgio. Nós nos preocupamos com nossas aulas e com nossa pesquisa e acho que fazemos bem, talvez você tenha razão. Bom, preciso ir agora Sérgio, preciso passar no supermercado para comprar algumas coisas. Um abraço e torça pelo meu time hoje à noite. Ah tá, pode deixar, ele vai ganhar de uns -5 a 3 [risos]. Um abraço.

Será que eu encontro uma vaga aqui, ali? Aqui não, aqui não também. Vou ter que ir para outro estacionamento. Aqui não, aqui... encontrei! Deixa eu pegar a lista agora, deixei dentro do livro de Análise, cadê, cadê... Aqui, aqui, encontrei. Júlio, é você? Sim sou eu. Nossa Júlio, quanto tempo. Como você está? Há quanto tempo não nos encontramos. Como anda a vida? Poxa, faz muito tempo mesmo. Esses dias, meus filhos e eu estávamos vendo as fotos da nossa formatura. O Sérgio estava, como sempre, muito magro e você com aquele cabelo enorme. Nossa, que legal! É, nós rimos muito. Eu encontro o Sérgio todos os dias na Universidade. Hoje mesmo conversamos sobre a universidade, lamentando algumas coisas, ele está bem. Mas me diga Júlio, como está seu trabalho? Olha, está muito corrido, mas muito gratificante. Gosto de trabalhar com as crianças e com os jovens. Grande parte deles começa o 
ano dizendo que odeia matemática, todos aqueles discursos prontos. Depois acabam o ano dizendo que até gostam e mesmo aqueles que continuam não gostando pelo menos entendem e veem um sentido nas discussões. É Júlio, você gosta mesmo da criançada. Gosto sim. Minha ideia é sempre construir junto com os alunos maneiras de lidar com o mundo em que estão vivendo. Minha intenção é transformar o modo deles pensarem. Fazer com eles leituras e oferecer outros modos de produzir significado. Para isso utilizo a matemática, mas também estabeleço relações com a Geografia, História, Biologia, entre outras disciplinas. Na verdade, nem seria a matemática, não seria aquela matemática que ficávamos horas e horas discutindo na universidade, durante a nossa graduação. Aquelas aulas com todos os axiomas, teoremas, demonstrações, todo o formalismo em como escrever... Você se lembra daquelas discussões que fazíamos, quando pegávamos dois, três livros diferentes para discutir como os autores demonstravam, como definiam os conceitos, quais exercícios eles resolviam. Na escola é diferente, faço outras coisas. Você se lembra Júlio, daquela prova de Análise, na qual você ficou discutindo com o professor que a sua demonstração para o teorema do sanduíche era equivalente à dele e que, no fundo, ele não sabia outra demonstração a não ser a dele, daquela velha folha amarela? Lembro, como lembro! Lembro que estudávamos muito e sabíamos demonstrar das duas maneiras e quais argumentos seriam utilizados para justificar a equivalência. Eu gostava das aulas de Análise, também adorava as aulas de estruturas algébricas. Era um tempo gostoso. Eu ainda não consigo entender porque você não seguiu carreira acadêmica. Você se lembra do professor de Variáveis Complexas? Ele dizia que você teria muito sucesso na pesquisa em matemática pura e que poderia até mesmo fazer um doutorado fora do país. Eu me lembro disso, cheguei até pensar em fazer mestrado e doutorado. Mas o que eu gosto é da escola básica. Gosto das crianças desenvolvendo o pensamento algébrico, gosto delas pegando os jornais dessas grandes lojas e entendendo os juros que estão escondidos nas propagandas, gosto das crianças entendo as poucas probabilidades de ganhar na Mega-Sena e o tanto de dinheiro que se arrecada em um mês com a Mega acumulada. Eu acho que optei por uma carreira mais local em que algumas mudanças eu pudesse ver em um curto período de tempo. Poxa, Júlio, é muito bom escutar você falando disso. Meu foco são as crianças e os jovens. As matemáticas, dizendo assim, entram como um meio. Eles estão estudando agora se o espaço que a escola tem é adequado ao número de alunos. Isso é muito legal. Estamos estudando a planta da escola, quantos metros quadrados seriam razoáveis para o bem estar de cada aluno. E por aí vai. Cada projeto que acaba indica novas ideias para novos projetos. Eles adoram. Muitas vezes, eles nem acham que estão nas aulas de matemática. Tem alguns professores que não gostam, mas eu sustento essa perspectiva e os pais também apoiam, eles veem mudanças significativas nas atitudes de seus filhos. A escola é um mundo e a matemática que fazemos lá também se constitui de maneira 
particular, meu velho amigo. Melhor dizendo, as discussões matemáticas que fazemos lá são bem diferentes da matemática que tínhamos na universidade. Diferentes daquelas aulas. Diferente da intenção. Diferente também, penso eu, da natureza do conhecimento. Como assim, Júlio? Explique um pouco mais dessas coisas que você está me falando... Eu nunca parei para tentar explicitar algumas diferenças em relação a isso e nem mesmo escrever algo. O que falo, falo da minha vivência e do que consigo enxergar. Há alguns artigos e livros que tratam dessa questão, de que a matemática da escola tem características específicas e diferentes da matemática da universidade. Outro dia eu assisti uma palestra de um pesquisador falando sobre essas coisas. Mas o que falo é mais em relação ao que sinto e ao que vivo. Nossa Júlio, nunca pensei nisso! Mas me explique um pouco melhor. Veja, você assim como eu e o Sérgio, estudamos muita matemática. Estudávamos a base da matemática, Júlio. Na escola tem uma matemática mais elementar, mas a base está na universidade. Está nas Estruturas Algébricas, na Análise, na Teoria dos Números, entre outras disciplinas. Eu acredito que todos aqueles anos de estudos serviram para dar uma base para você ser professor da escola básica. Pelo menos é isso que prego para os meus alunos da Licenciatura há mais de 20 anos na universidade, digo a eles que: mesmo que vocês não vão ensinar essa matemática da universidade, ela servirá de base para vocês darem aulas na educação básica. Essa é a base da matemática: Cálculo, Análise, Estruturas Algébricas. Essas disciplinas comuns que a gente tinha no nosso tempo de Graduação e permanecem até hoje na grade curricular do curso de licenciatura. Eu vivencio outras coisas, meu amigo. Para o meu trabalho, meus objetivos e minhas metas com meus alunos, eu preciso estudar muito a matemática da educação básica e mais, como eu educo meus alunos matematicamente, isso é o que é diferente. Matemáticas em uso, em processos, relacionadas às outras áreas do dia a dia, do cotidiano. Meu foco é o desenvolvimento dos alunos e não a matemática. Em minha realidade a matemática é apenas um meio. É, não sei Júlio, às vezes acho que estamos falando sobre as mesmas coisas, mas continue, estou curioso. Estudo os erros dos alunos para entender como eles constroem suas resoluções, como elaboram suas estratégias e procedimentos. Estudo como eles interpretam as diferentes representações. Estudo quais são as maneiras mais proveitosas de se introduzir um conceito e também estudo bastante como os alunos aprendem certas temáticas da matemática. Estudo que tipo de desenvolvimento de raciocínio matemático é importante para os alunos se desenvolverem cognitivamente e quais tipos de estratégias matemáticas são úteis para eles viverem e terem possibilidades de lidar com esse mundo de hoje. Nisso vejo que a matemática da escola é bem diferente daquelas discussões matemáticas que tínhamos na Licenciatura. Eu acho que a formação que eu tive, que nós tivemos, serviu para alguma coisa. Se você me perguntasse, talvez poderia parar, pensar e ver algumas coisas. Mas o fato é que eu vivo essas coisas. Sou suspeito para falar 
porque vivo apenas essa realidade, a da sala de aula da educação básica, mas é assim que eu vejo. Sérgio e eu estávamos hoje mesmo falando disso, de sempre olharmos para o mundo de dentro do lugar em que vivemos, no nosso caso de dentro da universidade. Damos nossas aulas, fazemos nossa pesquisa e acreditamos que nossa função é fazer isso da melhor maneira possível. Entretanto, nem mesmo questionamos o que fazemos. Mas Júlio, gostei de te encontrar. Passa qualquer dia lá na universidade para a gente conversar. Sérgio ficará feliz em revê-lo. Preciso ir agora, pois estou atrasado. Um abraço Júlio. Um abraço, também estou atrasado para o jantar.

Vou para casa jantar, depois assistir o jogo e voltar a procurar trabalhos daquele chinês. Como eles conseguem produzir tanto? São muitos trabalhos. Deixa agora eu ligar o computador, dar uma olhada nos e-mails. Engraçado, o Júlio falou umas coisas que eu nunca tinha pensando. Ele não trabalha com a matemática, ele faz discussões matemáticas. Que será que ele quis dizer com isso? Ele disse também que vivencia uma matemática em suas aulas e que durante sua formação, junto comigo e com o Sérgio, ele teve uma outra matemática. $\mathrm{O}$ Júlio conhece matemática, ele entende de demonstrações. Ele era um dos primeiros alunos da nossa turma. Ele não está engabelando as crianças, ele é sério, comprometido. O que será que ele quis dizer com isso? Matemáticas? Matemática de diferentes maneiras? Matemática em diferentes contextos? Será que a matemática do Júlio tem uma natureza diferente da matemática que eu e o Sérgio trabalhamos na universidade? Não! Não! Não pode ser. É uma matemática elementar, aqui na universidade nós trabalhamos com uma matemática mais avançada. Mas será que ele pode ter razão? Será? Não! Não! Não pode ser, pois a verdadeira tragédia está na inexorabilidade do seu inexpressivo, que é sua identidade nua. A matemática é única e o que diferencia são os níveis. Tem os níveis da educação básica, níveis elementares, e a partir disso vai se aumentando o nível, níveis superiores, da universidade. Bom, de qualquer forma agora estou encafifado com isso. Acho que os trabalhos do chinês vão ficar para outro momento, vou pensar um pouco sobre isso. Matemática da escola? Discussões matemáticas? O que é isso? Eu nunca dei aula na escola básica. Apenas me lembro dos meus professores do colégio e eles não faziam nada do que o Júlio me disse. Agora se é diferente ou mesmo se tem características diferentes eu tenho um problemão na minha vida. Nas minhas aulas, de Cálculo, Análise, meu discurso sempre foi, e ainda é: a matemática da universidade vai dar uma base para vocês darem aulas na educação básica trabalhando com a matemática elementar, é a base da matemática. Será que essa formação, e estou pensando na formação matemática, porque eu sei que também tem o pessoal da Educação e da Educação Matemática que discute questões pedagógicas, psicológicas, o que também vejo que é importante, mas será que essa formação matemática é adequada para o professor da educação básica? Tem que ser. Mas, vamos olhar o caso do Júlio, ele era um 
brilhante acadêmico, tirava as melhores notas e estudava muito. Encontro com ele e me diz que para dar as aulas ele precisa estudar muitas coisas dessa matemática da escola. Estou perplexo. Não entendo. Estou angustiado. Durante anos trabalhei assim. Damos nossos cursos de matemática, discutimos matemática formalmente, nos preocupamos com a escrita dos nossos alunos, como se encadeia o modo axiomático dedutivo de se construir a matemática. Os professores da educação básica precisam conhecer essa matemática, a matemática da universidade é importante para eles. Mas veja, lembrando um pouco do que o Júlio disse, ele vivencia um outro mundo. Será que no mundo dele, da matemática da escola, essas coisas não têm relevância? Ele ainda disse que as discussões, a natureza do conhecimento que ele constrói com os alunos dele nem passam perto do mundo da matemática da universidade. Estou mais angustiado, estou sem saber o que dizer. Não, ainda é pior, estou sem saber o que pensar, não me vem nada à cabeça, matemáticas, matemática... Fiquei imóvel, calculando desordenadamente. Estava atenta, eu estava toda atenta. Em mim um sentimento de grande espera havia crescido, e uma resignação surpreendida: é que nesta espera atenta eu reconhecia todas as minhas esperas anteriores, eu reconhecia a atenção de que também antes vivera, a atenção que nunca me abandona e que em última análise talvez seja a coisa mais colada à minha vida - quem sabe aquela atenção era a minha própria vida.

Bom dia Sérgio, tudo bem? Tudo e com você? Feliz da vida, meu time ganhou de 5 a 3, 5 positivo, apenas para esclarecer, viu? [risos]. O atacante deu um show de bola nos zagueiros. Ah, foi sorte, foi sorte do seu time. Sérgio, você lembra do Júlio, aquele amigo nosso da graduação, bom pra caramba em resolver problemas, um geniozinho em visualizar demonstrações; aquele que fazia aqueles desenhos perfeitos no quadro, de paraboloides, esferas, cubos. Você se lembra dele? Sim, sim claro que eu lembro. Então, ontem depois da nossa conversa encontrei com ele no supermercado e ficamos conversando um pouco sobre a vida e bastante sobre o trabalho dele. Até por conta daquela nossa rápida conversa na sala do café. Você se lembra que ele só fez a graduação e parou por ali. Hoje ele trabalha em escolas públicas com a criançada e tem vários projetos sobre matemática. Ele me contou um pouco do como ele trabalha e de que matemática ele faz na escola. Sérgio, você está com tempo, tem aula agora? Não. Tenho tempo sim, podemos conversar. Ele me disse algumas coisas que a princípio nem dei muita atenção. Mas depois aquilo começou fazer um certo sentido, aí fiquei intrigado, angustiado e agora não consigo parar de pensar nessas coisas. Estou perplexo, e pior, estou em um momento que não sei o que dizer e nem mesmo o que pensar. Ele falou de coisas que me fizeram pensar, coisas que têm argumentos interessantes, apesar de falar de uma situação um tanto quanto nebulosa, mas coisas que provocaram uma perplexidade nos meus 20 anos de professor de curso de licenciatura de matemática e que me fizeram pensar na minha prática diária em ser professor e ensinar essa matemática que ensinamos para 
professores que irão para as escolas da educação básica. Calma, o que ele disse e o que você pensou? Nas palavras do Júlio, a matemática da escola, vamos assim dizer, é bem diferente da matemática da universidade, os Cálculos, a Análise. Ele disse que tem que estudar muitas coisas relacionadas à matemática da escola e que na vivência dele enxerga que o mundo da matemática da escola é um, e o mundo da matemática da universidade é outro. Não pode ser, o Júlio deve estar de brincadeira. Pior Sérgio, tanto eu quanto você nunca demos aulas na Educação Básica, não temos vivência e nem experiência com esse contexto. Engraçado como as coisas acontecem, você se lembra que ontem estávamos conversando sobre olhar para os problemas apenas com os olhos daqui de dentro da universidade. É, eu lembro... Então, o que você acha disso? Veja meu amigo, precisamos conversar mais com o Júlio, mas o que vem à minha cabeça é o seguinte, os professores da educação básica precisam estudar a base da matemática, que são as disciplinas que temos aqui na graduação para que com isso eles tenham condições de atuar na educação básica ensinando matemática. O que se tem na escola básica são exemplos particulares das estruturas matemáticas que temos aqui na graduação. Claro, graduação ainda é um nível muito rudimentar. A estrutura, estrutura mesmo temos nos mestrados e doutorados. Foi exatamente a primeira coisa que eu pensei, foi o primeiro argumento que me veio à cabeça. Veja, é preciso estudar limite no Cálculo, porque derivada, integral, no fundo são limites. Os alunos precisam estudar grupos, anéis, corpos, pois essa é a base da matemática, pelo menos nesse contexto da graduação. Eles precisam estudar Análise para fundamentar as temáticas que eles viram no cálculo por meio das demonstrações. Depois com todas essas coisas, fica fácil para um futuro professor pegar um livro de $6^{\mathrm{a}}$ série do Ensino Fundamental, ler, entender e dar uma aula. Isso para mim é o certo, não consigo imaginar outra formação. Então Sérgio, eu também penso assim como você, mas o Júlio dizia que as discussões matemáticas e a intenção de se trabalhar com matemática na educação básica é diferente da maneira como é feita aqui universidade. Ele falou em algo nesse sentido: educar matematicamente os alunos, desenvolver modos dos alunos lidarem com as situações do dia a dia. Veja, Sérgio, ele também disse que estuda muito a matemática da escola, estuda erros dos alunos, como eles aprendem os conceitos, que tipo de problema é mais interessante ao se começar uma discussão. Eu não sei o que falar sobre isso. Mas vejo que esse primeiro argumento que você me disse, que foi o primeiro que eu também disse para o Júlio, é fraco se pensarmos que a matemática da escola é diferente da matemática da universidade. Concorda comigo? Espera, deixa eu pensar... Se a matemática da escola for outra matemática, esse argumento é fraco mesmo. Mas não é outra, não pode ser outra. Matemática é única, universal! Sempre vi e vivi isso. Toma o que eu vi: pois o que eu via com um constrangimento tão penoso e tão espantado e tão inocente, o que eu via era a vida me olhando. O Júlio também dizia que lá na escola ele discute matemática não com o foco na matemática, mas sim 
no desenvolvimento dos alunos. Ele disse o importante não é a matemática e sim os alunos, a matemática é um meio, e ele disse que faz muitas relações com outras áreas como Geografia, História, Biologia, Música e também com conhecimentos não disciplinares, que não se enquadram nessas áreas. Sérgio, será que a matemática que discutimos com nossos alunos, da maneira como discutimos oferece uma formação matemática adequada para os futuros professores da educação básica? Porque as coisas que o Júlio disse que estuda para dar aulas, nós nem passamos perto de discutir aqui na Licenciatura. Na Análise, os alunos precisam aprender a demonstrar e aprendem isso demonstrando teoremas. Na Álgebra Linear eles aprendem transformações, auto valor e auto vetor, esse é o foco. Precisamos conversar mais com o Júlio e também com outros professores. Acho que precisamos sair dos muros da universidade. Também acho Sérgio. Precisamos tentar entender. Mas o que faço agora: tenho que dar aula de Análise daqui a 15 minutos no terceiro ano da Licenciatura, o que falo para eles. Conto minha perplexidade? Divido esse meu estranhamento com eles? Ou simplesmente esqueço que encontrei o Júlio ontem e conversamos todas essas coisas. Não consigo esquecer, pois não sai da minha cabeça. Não sei, meu amigo, o que você deve fazer, não sei. Sérgio, então... depois conversamos mais, um abraço. eu estava no deserto como nunca estive. Era um deserto que me chamava como um cântico monótono e remoto chama.

Bom, deixa eu me concentrar para a aula e depois penso nisso. Vou voltar para meu dia a dia e deixar o "Júlio" para uma outra hora. Deixe-me olhar minhas anotações, tenho que rever isso, demonstrar esse teorema, aquele outro, e introduzir essa ideia. Certo, deixe-me pegar um copo de água, vamos para aula. Bom pessoal, então é isso, por hoje chega. Não se esqueçam de estudar essas questões e qualquer dúvida me procurem.... Professor, podemos conversar um instante agora no fim da aula? Sim claro. Estava pensando em fazer alguma iniciação científica em Análise, queria discutir algum assunto com mais profundidade. $\mathrm{O}$ senhor sempre diz que essa disciplina é a base da matemática, eu quero aprender mais. Eu quero ser professor da educação básica, esse é meu foco, e eu acho que estudar mais Análise pode me ajudar no futuro enquanto professor. Talvez, com estudos mais profundos e sólidos eu possa entender melhor a matemática daqui da universidade e por consequência a matemática da educação básica. Mas quero estudar mesmo, ir a fundo e entender. Quero ser um bom professor de matemática para meus alunos. Quero trabalhar com a criançada, o senhor poderia me orientar? Olha, como é seu nome mesmo. Jamur, professor, meu nome é Jamur. Então Jamur, podemos pensar em algo nesse sentido. Eu gosto muito de trabalhar com iniciação científica com alunos da graduação. Passe na minha sala no final da semana para conversarmos mais sobre isso.

Não, não, não pode ser... é muita ironia do destino um aluno querer fazer uma iniciação científica em Análise porque ele quer aprender mais sobre essa disciplina para 
ajudá-lo no ofício de professor de matemática da Educação Básica. Ele quer aprender mais profundamente, para ter um conhecimento sólido. Não pode ser. O que falarei para ele no final da semana? Pedirei ao Júlio para falar com ele? Não posso. O Júlio não é nem professor da Universidade. Bom deixe-me ir para casa depois penso nisso. Mas pensar o que se eu nem consigo imaginar o porquê eu falo dessa matemática para meus alunos. Pensar no que e sobre o que, se essa formação pode ser que não tenha nenhuma validade para os alunos? Tudo bem, fico contente que eles saibam muito sobre Análise, mas e quando eles chegarem na frente da criançada, o que irão fazer? Chega, vou pensar nos problemas do chinês, vou tentar me concentrar em outra coisa. Aquilo que se vive - e por não ter nome só a mudez pronuncia -é disso que me aproximo através da grande largueza de deixar de me ser. Não porque eu então encontre o nome do nome e torne concreto o impalpável - mas porque designo o impalpável como impalpável, e então o sopro recrudesce como na chama de uma vela.

Já é sexta-feira e o Jamur deve estar chegando daqui a pouco na minha sala. Será que ele vem? Bem que ele poderia não vir. Assim, teria um fim de semana para pensar nisso. Professor, posso entrar? Só porque eu acabei de comentar... Entra Jamur, tudo bem? Estava mesmo te esperando. Então professor, vim aqui falar com o senhor sobre a iniciação científica. Gostaria de fazer alguma coisa ligada à Análise. Pelo que o senhor e os outros professores do curso dizem, é uma disciplina muito importante, senão a mais, do curso de matemática. Se eu fizer uma iniciação nessa área vou ter uma formação mais sólida e profunda e isso com certeza vai me ajudar a ser professor da educação básica, que é o meu objetivo. Como lhe disse, sempre quis trabalhar com a criançada, sempre foi meu sonho. Quero ralar mesmo, estudar bastante... O senhor poderia me orientar? Então Jamur, poderia sim. Para mim é sempre um prazer orientar iniciação científica ainda mais para alunos esforçados e comprometidos como você. Você chegou a pensar em algum tema específico? Ainda não e isso até que eu queria te perguntar: que tema seria interessante para eu ter essa formação sólida em matemática que a Análise pode me oferecer, claro que pensando na educação básica? [Não acredito... olha a pergunta que esse aluno está me fazendo; todos meus 20 anos de professor universitário e essa pergunta simples eu não consigo responder. Como pode isso? Isso não pode estar acontecendo. E agora ele está aqui em minha frente e não tenho o que dizer] Professor? Professor? Desculpe, Jamur, estava pensando aqui comigo. Se abandono a esperança, estou celebrando a minha carência, e esta é a maior gravidade do viver. E, porque assumi a minha falta, então a vida está à mão. Muitos foram os que abandonaram tudo o que tinham, e foram em busca da fome maior. Jamur, nesses últimos dias, e isso vou te confessar, essa é uma das perguntas que eu não tenho a menor ideia por onde começar para te responder. Deixa eu te explicar. Faz uns três dias eu encontrei um velho amigo meu da graduação. Ele não fez mestrado, nem doutorado e desde a época em que se 
formou só dá aula na Educação Básica, Ensino Fundamental e Médio. Ele era, e acho que ainda é, um gênio da matemática. Estudava muito. O professor Sérgio também o conhece. Você sabe que Sérgio e eu estudamos juntos, não sabe? Estudaram, nossa que legal. Também estudamos com o Júlio, esse meu amigo sobre o qual estou lhe falando. Nós devorávamos os livros. Então, eu falei com o Júlio e ele me contou um pouco do trabalho dele e das discussões matemáticas que ele faz com seus alunos, ele usou esse termo, discussões matemáticas. Então, vou encurtar a história, ele me deixou sem resposta para as seguintes perguntas: Será que a matemática que discutimos aqui na universidade, essas disciplinas centrais, Cálculo, Análise, Estruturas Algébricas, Teoria dos Números, entre outras, dão suporte, são adequadas, para formar matematicamente os professores que vão atuar na educação básica? Indo além, será que a matemática da escola é diferente da matemática da universidade? Nossa professor, nunca pensei nisso! Para você ver. Em que ponto a matemática acadêmica ajudaria o professor da educação básica? Por que temos essa formação matemática nas licenciaturas? Por que faz mais de vinte anos que tenho esse discurso de que meus alunos precisam aprender matemática? Por que... E talvez, formulando agora mais uma pergunta, que discurso sustenta a formação matemática do futuro professor de matemática da educação básica em sua formação inicial? Professor, nunca parei para pensar nisso. Nem sei direito se entendi essas perguntas que o senhor fez. Veja Jamur, eu também não tenho respostas. Às vezes me faltam palavras. Professor, vamos pensar um pouco. Desde o primeiro ano a gente escuta aqui no curso de matemática, que essas disciplinas que o senhor citou são a base do conhecimento matemático e mesmo que a gente não vá falar de supremo, de ínfimo na educação básica, precisamos conhecer isso porque são os conhecimentos que nos dão os suportes, a formação sólida e profunda da matemática. Eu escuto isso desde o primeiro ano. E eu falo isso há 20 anos, Jamur. Essas perguntas que o senhor coloca me fazem pensar em todo esse discurso que venho escutando e acreditando desde os primeiros anos de faculdade. Eu te dou razão e também entendo o que está me dizendo, Jamur. E agora professor? Agora eu não sei... Bom Jamur, vamos pensar mais sobre isso. Talvez possamos convidar o Júlio para bater um papo. Podemos conversar com o Sérgio, outros colegas nossos daqui do departamento, não sei. A gente tem um tempo ainda para mandar o projeto de sua iniciação, não tem? Temos sim professor. Então, vamos conversando sobre isso. Tudo bem, vou pensar nisso também professor.

Vou para casa. Já é tarde. E hoje, novamente não olhei os problemas do chinês, vou ter que arrumar um tempinho no fim de semana. Parece que o Jamur entendeu minhas angústias. Que será que ele está pensando agora? Bom, pelo menos fui sincero com ele e, primeiramente, comigo. Meu Deus, veja que coisa: Não estou à altura para falar sobre qual matemática o futuro professor precisa aprender na licenciatura. Mas eu tenho que falar, 
preciso falar. Eu sou um matemático. Preciso ter claro isso para mim. Como eu posso ter esses questionamentos? Agora? Por quê? A matemática é a matemática. Será? Estou tentando te dizer como cheguei ao neutro e ao inexpressivo de mim. Não sei se estou entendendo o que falo, estou sentindo - e receio muito o sentir, pois sentir é apenas um dos estilos de ser. No entanto atravessarei o mormaço estupefato que se incha do nada, e terei que entender o neutro como sentir. Bom, amanhã é sábado vou esquecer um pouco da universidade, vou curtir minha família. Pai, Pai... Oi filha tudo bem, o que aconteceu? Deixa eu te contar, acabei de ler um livro sobre angústias, estranhamentos, epifanias, barata, paralisações, uma tal de G.H, sobre paixão também. Nossa pai, é um livro muito estranho, cheio de angústias e questionamentos sobre a vida, denso. Parei várias vezes para respirar e tentar esquecer. Parecia que ele me chamava para ler, me seduzia. Me senti atropelada pelas palavras, pelas frases, pelo enredo como um todo. A mulher fica muito tempo pensando sobre a vida dela e também sobre o mundo. Fiquei muito angustiada. É filha, talvez ela chegou ao extremo de perplexizar-se, angustiar-se, estranhar-se, sair da realidade mundana. Talvez, ela tenha precisado disso para entender ou se perder no mundo dela, não é tão estranho assim não, pois só quando erro é que saio do que conheço e do que entendo. Se a "verdade" fosse aquilo que posso entender - terminaria sendo apenas uma verdade pequena, do meu tamanhol.

1. A ficção não tem a ver com a fantasia, nem mesmo com o avesso da realidade. A ficção é apenas mais um modo de produzir significados, um movimento que poder ser de teorização.

2. A ficção é processo. É sendo e sempre apenas esta. Assim como processos da ciência, da matemática.

3. A ficção é movimento de inventar mundos, inventando-se neles. Um movimento entre o dito e o não dito. Entre a vírgula e a palavra que segue. Entre o que se escapa e o que se sente. Entre estranhamentos e outros (novos) horizontes culturais.

4. A verdade e A religião (enquanto instituições) sempre travaram embates com a ficção. Não apenas por argumentos filosóficos. Muito por impor a manutenção da cultura dominante, de seus modos, ritos e mitos.

5. Está é uma obra de realidade. Qualquer semelhança com a ficção é mera coincidência. Perde-se algum valor? Perde-se alguma potência de pensamento?

\footnotetext{
${ }^{1}$ Os trechos em itálicos são fragmentos do livro A Paixão Segundo G.H. de Clarice Lispector. Livro que me inspirou na produção/invenção deste texto. Eles não são citações e não buscam uma sistematicidade, motivo pelo qual dispensa os números das páginas de onde foram tirados. Os fragmentos atentam (apenas em tentativas já fracassadas) para sensações, para provocações nos dilemas desse professor de matemática.
} 
6. A ficção oferece possibilidade de problematizar o naturalizado, o que pulsa todos os dias e, ao mesmo tempo, se esconde para fazer a manutenção do que pode ou não ser dito.

7. A ficção é poética, pois inaugura e reinaugura a cada vez o mundo, que não se fundamenta na razão, nem se posiciona contrário, como irracionalidade ou subjetividade, mas se funda como sentido (FERRITO, 2014).

8. Para se ser apoderável por ficção é preciso não ser. Se eu fosse casa escolhia ser janela. Porque a janela é da casa o que não é, o vazio onde ela sonha ser mundo. A vida [como uma que se inventa nesses rascunhos] é a estrada andando sob o pé do tempo (COUTO, 2015) ${ }^{\text {ii }}$.

9. Tudo o que não invento é falso (BARROS, 2010).

\section{Referências}

BARROS, M. Poesia Completa. São Paulo: Leya, 2010.

COUTO, M. Na berma de nenhuma estrada. O escrevido. São Paulo: Companhia das Letras, 2015. p. 145.

FERRITO, R. Ficção. In: CASTRO, M. A. (Org.) Convite ao pensar. Rio de Janeiro: Tempo Brasileiro, 2014. p. 98.

LINS, R. C. O Modelo dos Campos Semânticos: estabelecimentos e notas de teorizações. In: ANGELO, C. L. et al. (Org.). Modelo dos Campos Semânticos e Educação Matemática - 20 anos de história. 1ed. São Paulo: Midiograf, p. 10-20, 2012.

LISPECTOR, C. A paixão segundo G. H. Rio de Janeiro: Rocco, 1998.

VIOLA DOS SANTOS, J. R. Legitimidades possíveis para a Formação Matemática de Professores de Matemática (Ou: Assim falaram Zaratustras: uma tese para todos e para ninguém). 2012. 360p. Tese (Doutorado em Educação Matemática) - Instituto de Geociências e Ciências Exatas, Universidade Estadual Paulista, Rio Claro, 2012. Disponível em: <http://hdl.handle.net/11449/102099> Último acesso: 20/11/2018.

VIOLA DOS SANTOS, J. R.; LINS, R. C. Movimentos de Teorizações em Educação Matemática. BOLEMA: Boletim de Educação Matemática (Online), v. 30, p. 325-367, 2016. Disponível em: http://www.scielo.br/pdf/bolema/v30n55/1980-4415-bolema-30-55-0325.pdf . Último acesso: 20/11/2018.

\section{SOBRE O AUTOR}

JOÃO RICARDO VIOLA DOS SANTOS. Licenciado em Matemática (2004) pela Universidade Estadual de Londrina, Mestre em Educação Matemática (2007) pelo Programa de Pós-Graduação em Ensino de Ciências e Educação Matemática da Universidade Estadual de Londrina. Realizou estágio, durante o mestrado, na Universidade de Miami, Estados Unidos (2006). Doutor em Educação Matemática (2012) pelo Programa de Pós-Graduação em Educação Matemática da UNESP de Rio Claro. É professor Adjunto do Instituto de Matemática da Universidade Federal de Mato Grosso do Sul e atua no Programa de PósGraduação em Educação Matemática (Mestrado e Doutorado). Principais interesses de pesquisa: Formação de Professores que Ensinam Matemática e Avaliação e Educação Matemática. Atualmente é diretor da Sociedade Brasileira de Educação Matemática 
Regional MS (2015-2018), Vice Coordenador do Grupo de Trabalho de Avaliação e Educação Matemática da SBEM (2015-2018) e vice-editor da Revista Perspectivas da Educação Matemática.

\footnotetext{
${ }^{\mathrm{i}}$ FERRITO, R. Ficção. In: CASTRO, M.A. (org.) Convite ao pensar. Rio de Janeiro: Tempo Brasileiro, p.98, 2014.

${ }^{\text {ii }}$ COUTO, M. Na berma de nenhuma estrada. O escrevido. São Paulo: Companhia das Letras, p.145, 2015
} 